\title{
Fiscal, monetary policy and the conditional risk premium in short-term interest rate differentials: an application of Tobin's portfolio theory
}

\author{
Thomas J. Flavin ${ }^{\mathrm{a}, *}$, Michele G. Limosani ${ }^{\mathrm{b}}$ \\ a Department of Economics, National University of Ireland Maynooth, Co. Kildare, Ireland \\ ${ }^{\mathrm{b}}$ Universita degli Studi di Messina, Facolta di Scienze Politiche, Dipartimento di Economia, \\ Via T. Cannizzaro, is.278, 98122 Messina, Italy
}

Received 20 October 2003; received in revised form 15 September 2004; accepted 5 October 2004 Available online 4 January 2005

\begin{abstract}
This paper proposes a Multivariate-Arch in Mean model to analyze the potential channels through which domestic fiscal and monetary policy as well as changes in the international economic environment may affect interest rate differentials across countries. This technique is illustrated by analyzing the behavior of short-term interest rates in a number of European countries prior to the introduction of the common currency. The key feature of our results is that macroeconomic variables exert both a direct and indirect influence on the shortterm interest rate differential. This indirect effect is captured through the conditional volatility of the differential, which is itself a statistically significant determinant of the level of the differential. This relationship is likely to be overlooked by more traditional models that focus solely on the first order moments of the process.

(C) 2004 Elsevier Inc. All rights reserved.
\end{abstract}

JEL classification: E43; E44; G15

Keywords: Interest rate differentials; Macroeconomic effects; M-GARCH

* Corresponding author. Tel.: +3531 7083369; fax: +35317083934.

E-mail address: thomas.flavin@may.ie (T.J. Flavin).

1059-0560/\$ - see front matter (C) 2004 Elsevier Inc. All rights reserved.

doi:10.1016/j.iref.2004.10.006 


\section{Introduction}

It is quite common, and indeed consistent with financial economic theory, to observe interest rate differentials across countries. These differentials also tend to vary over time, telling us that some factor, or set of factors, is causing this variation. These time-varying differentials are most usually explained in terms of a (conditional) ${ }^{1}$ risk premium attached to the debt instruments of one country above another, either due to economic or political uncertainty. ${ }^{2}$ However, until we have a better understanding about the source of the risk premium, attempts to adequately explain its existence and predict its future movements will prove difficult to achieve. The aim of this paper is to analyze the potential channels through which macroeconomic variables may affect interest rate differentials across countries. We identify a set of potentially important variables from the work of Tobin and examine their importance for explaining short interest rate differentials within Europe during the period of the EMS. There will undoubtedly be other candidate variables but this work offers a first attempt to model the link between interest rate differentials and the wider macroeconomic environment. ${ }^{3}$

Portfolio theory implies a risk- return trade-off and therefore investors have to be compensated for holding more risk by earning a higher return on government debt instruments. Asset risk is usually measured in terms of the (conditional) volatility of its return but it is our conjecture that other risk sources may also contribute to the overall risk of an asset. Consequently, volatility in the wider economic environment may be transmitted to government bonds. Such contagion effects will cause any potential investor to seek even more compensation in the form of a greater required return. Tobin's work on portfolio selection provides some insight to identify potential sources of the risk premium. These factors have both a direct and indirect impact on the level of the differential. The indirect or second-order effect stems from the impact of the conditional volatility on the risk premium. Our methodology investigates the empirical evidence of such effects. Kim and Kim (2003) have already noted their importance from a theoretical modeling perspective. They stress the potential influence of second-order effects as a stimulus for monetary policy theorists. The presence of a conditional risk premium for currency markets has already been documented by Hodrick (1987) and for futures markets by Hess and Kamara (2002).

In order to analyze and identify the potential channels by which macroeconomic variability may influence both the conditional mean and conditional volatility processes of the short-term interest rate differentials, we propose a Multivariate Autoregressive Conditional Heteroscedasticity (MARCH) in-mean model. This family of models has been extensively applied to assessing the impact of macroeconomic sources of risk in currency markets (Wickens \& Smith, 2002), in currency futures markets (Baum \& Barkoulas, 1996) and in Treasury bill futures markets (Hess \& Kamara, 2002). The factors we employ can be loosely interpreted as being proxies for monetary and fiscal policy as well as changes in the international economic environment. By jointly modeling the financial asset returns and the macroeconomic variables, we can immediately assess the influence of

\footnotetext{
${ }^{1}$ Hodrick (1987) shows for currency markets that even when the unconditional risk premium is zero, this does not rule out the existence of a non-zero conditional risk premium.

${ }^{2}$ For further discussion, see Frankel and MacArthur (1988) and Limosani (2000).

${ }^{3}$ In an earlier paper, Flavin and Limosani (2000) use a univariate ARCH model to show that the debt/GDP ratios of European countries helped to explain movements in risk premia vis-à-vis Germany.
} 
these variables on both the conditional mean and conditional second-order moments of the interest rate differential.

The paper is structured in the following way: the second section provides a sketch of the theoretical framework. The third section contains a description of the empirical model. The fourth section presents and discusses the empirical results while the final section provides some concluding remarks.

\section{Theoretical background}

Portfolio theory (Constantinides \& Mallaris, 1995; Markowitz, 1952; Tobin, 1958, 1982) provides a loose rationale for modeling the demand for a domestic asset as a function of the structure of expected yield.

The demand function for domestic government bonds in real terms can be expressed as:

$$
\left(\frac{B^{\mathrm{d}}}{p}\right)_{t}=f\left[(i-\pi)_{t}-\left(i^{*}-\pi^{*}-E_{t} \Delta S_{t+1}\right)_{t},\left(\frac{Y}{p}\right)_{t},\left(\frac{W}{p_{t}}\right), \sigma_{t}^{2}\right]
$$

where all the variables marked with * refer to the foreign country and $\left(B^{\mathrm{d}} / p\right)$ the real demand for bonds of a domestic investor, $i$ is the nominal interest rate on the relative asset and $\pi$ is the inflation rate. The first element within the square bracket represents the real ex-ante excess return of a domestic asset with respect to a foreign asset with similar characteristics. $Y$ is nominal income, taken as an indicator of capital market imperfection; $W$ is financial wealth; $\sigma_{t}^{2}$ is the conditional variance representing the underlying risk of the asset arising from the uncertainty of asset returns.

Expressing the demand for government bonds as a proportion of nominal GDP, Eq. (1) can be written as: ${ }^{4}$

$$
b_{t}=f\left\lfloor(i-\pi)_{t}-\left(i^{*}-\pi^{*}-E_{t} \Delta S_{t+1}\right)_{t}, w_{t}, \sigma_{t}^{2}\right\rfloor
$$

where the lower case letters, $b$ and $w$, denote that the corresponding upper case variables have been divided by nominal income.

This equation can be interpreted as an implicit function of the form:

$$
F\left[(i-\pi)_{t}-\left(i^{*}-\pi^{*}-E_{t} \Delta S_{t+1}\right)_{t}, w_{t}, \sigma_{t}^{2}, b_{t}\right]=0
$$

which can be solved as:

$$
\left(i-i^{*}\right)_{t}=\varphi\left(\left(\pi-\pi^{*}\right)_{t}, E_{t} \Delta S_{t+1}, w_{t}, \sigma_{t}^{2}, b_{t}\right)
$$

Assuming that the ratio $W / Y=w$ changes very slowly and therefore remains constant $(k)$ through time, Eq. (4) expresses a relationship between the short-term interest rate differential, the debt/GDP ratio, the inflation rate differential and the conditional variance. Assuming that in the steady state position $\pi$ is a

\footnotetext{
${ }^{4}$ We implicitly are assuming the demand function to be homogenous in nominal income.
} 
function of $\pi$ and $E_{t} \Delta S_{t+1}$ as suggested by the Purchasing Power Parity (PPP) condition, Eq. (4) can be expressed only in terms of domestic variables and the exchange rate of the domestic country vis-à-vis the foreign country as follows:

$$
\left(i-i^{*}\right)_{t}=\varphi\left(k, \pi, E_{t} \Delta S_{t+1}, b_{t}, \sigma_{t}^{2}\right)
$$

Eq. (5) suggests that short-term interest rate differentials depend not only on a set of macroeconomic variables such us the domestic inflation rate, the debt/GDP ratio and the expected rate of depreciation of the exchange rate but also on their own volatility, as expressed by its conditional variance. The first two variables moreover may be loosely interpreted as monetary and fiscal policy instruments while the exchange rate may be thought of as capturing international effects.

From a theoretical point of view we should not expect asset demand functions to be stable in the face of significant variations in the economic environment. In particular the variance-covariance matrix of returns may reflect the probability distribution of more fundamental shocks in the economy such as government policies as well as foreign economies. Different approaches to modeling the conditional variance have been suggested in the empirical literature on international finance. The first approach would be to consider a constant variance following Frankel (1982). An alternative approach could be to assume that the conditional variance varies over time using a (G)ARCH(M) model introduced by Bollerslev (1986) and Engle (1982). A final approach is to allow the conditional variance to be influenced by time-varying macroeconomic factors like Clare, O'Brien, Thomas, and Wickens (1998).

Our main innovation is to use a M-ARCH-in mean approach to capture the transmission process by which the domestic inflation rate, the debt/GDP ratio and the depreciation rate of the exchange rate may exert either a direct influence in determining the level of the differential or an indirect impact through their effects on the conditional variances and covariances of the process. This approach creates a more plausible link between the financial world and the macroeconomy and appears to be most consistent with portfolio theory.

\section{The empirical model}

The family of (G)ARCH models are particularly well-suited to capturing time variation in the covariance matrix of asset returns. However, the computational burden involved in estimating multivariate $(\mathrm{G}) \mathrm{ARCH}$ models is quite considerable and is often sufficiently cumbersome to prevent its empirical application. ${ }^{5}$ We adopt the parameterization of Flavin and Wickens (2003). This formulation seeks to retain the parsimony of the other representations while simultaneously offering the user additional potentially important information that is ignored by other models. The main innovation of the new representation consists of writing the conditional second-order moments in error correction format thereby decomposing them into the sum of their long-run and short-run components. This is then combined with the BEKK representation so as to ensure that the resulting time-varying covariance

\footnotetext{
${ }^{5}$ For a complete review of this topic and alternative formulations, see Bollerslev, Engle, and Nelson (1994).
} 
matrices are symmetric and positive definite. The Flavin and Wickens parameterization ${ }^{6}$ for a multivariate GARCH model can be written as follows;

$$
\begin{aligned}
& Y_{t}=c+\varepsilon_{t} \\
& \varepsilon_{t} \mid \Psi_{t-1} \sim N\left(0, H_{t}\right) \\
& H_{t}=\mathbf{V}^{\prime} \mathbf{V}+\mathbf{A}^{\prime}\left(\varepsilon_{t-1} \varepsilon_{t-1}^{\prime}-\mathbf{V}^{\prime} \mathbf{V}\right) \mathbf{A}+\mathbf{B}^{\prime}\left(H_{t-1}-\mathbf{V}^{\prime} \mathbf{V}\right) \mathbf{B} .
\end{aligned}
$$

This parameterization has a number of advantages over the more general formulation. First, it offers a significant reduction in the number of parameters to be estimated. Now $\mathbf{V}, \mathbf{A}$ and $\mathbf{B}$ are all $\left(\begin{array}{lll}n & x & n\end{array}\right)$ symmetric matrices requiring the estimation of $3 \times[n(n+1) / 2]$ parameters in total. Second, by formulating the conditional variance-covariance structure in this way, we get an estimate of both the long-run conditional covariance matrix together with its short-run dynamics. This is important as it allows us to decide if the short-run dynamics have a contribution to make and if they are worthy of the time and effort required to estimate them. It also allows us to isolate and identify the sources of the short-run action, i.e. which parameters are most significant in determining the deviations from the long-run value. This could be an important source of information in problems of a larger dimension in which the author may want to restrict the number of parameters to estimate. Third, by combining this parameterization with a variant of the BEKK representation, we have guaranteed that the conditional variance-covariance matrix of asset excess returns is positive definite.

\subsection{Our application}

In our application, a multivariate ARCH specification of the model was found to be sufficient to capture the second-order moments of the process. Hence a M-ARCH version of Flavin and Wickens (2003) is adopted to investigate the potential link between short interest rate differentials across European countries and the macroeconomic variables identified in the previous section. We also enrich the conditional mean specification by including the first lag of the variables (to capture any persistence) and allowing the conditional volatility of the interest rate differential to influence its level, thus rendering the model a M-ARCH-in-mean model. This econometric approach allows the macroeconomic variables to influence both the conditional mean and covariance structure of the short-interest rate differential between each country and Germany, our benchmark country. The MARCH structure is ideally suited to this type of analysis as it captures the time variation in the premium while at the same time being consistent with many of the stylized facts of asset prices such as thick tails and volatility clustering.

We estimate a four variable M-ARCH-in-mean model as follows for each country;

$$
\begin{aligned}
& x_{t}=\alpha+\beta x_{t-1}+\gamma h 1_{t-1}+\varepsilon_{t} \\
& \varepsilon_{t} \mid \Psi_{t-1} \sim N\left(0, H_{t}\right) \\
& H_{t}=\mathbf{V}^{\prime} \mathbf{V}+\mathbf{A}^{\prime}\left(\varepsilon_{t-1} \varepsilon_{t-1}^{\prime}-\mathbf{V}^{\prime} \mathbf{V}\right) \mathbf{A} .
\end{aligned}
$$

\footnotetext{
${ }^{6}$ This parameterization is consistent with the covariance stationary model developed in Engle and Kroner (1995).
} 
Table 1

Results of Hansen's parameter stability tests

\begin{tabular}{llllll}
\hline Panel A: Eq. (1) & \multicolumn{3}{c}{} & & \\
\hline & $\boldsymbol{\beta}_{11}$ & $\boldsymbol{\beta}_{12}$ & $\boldsymbol{\beta}_{13}$ & $\boldsymbol{\beta}_{14}$ & 0.03 \\
\hline UK & 0.16 & $0.60^{*}$ & 0.05 & 0.18 & $0.56^{*}$ \\
France & 0.03 & $0.51^{*}$ & 0.19 & 0.08 & $0.86^{*}$ \\
Italy & 0.09 & 0.32 & 0.08 & $1.16^{*}$
\end{tabular}

Panel B: Eq. (2)

\begin{tabular}{llllll}
\hline & $\boldsymbol{\beta}_{21}$ & $\boldsymbol{\beta}_{22}$ & $\boldsymbol{\beta}_{23}$ & $\boldsymbol{\beta}_{24}$ & \multicolumn{2}{c}{} \\
\hline UK & 0.08 & 0.39 & 0.19 & 0.05 & 0.09 \\
France & 0.07 & 0.23 & 0.04 & 0.18 & 0.05 \\
Italy & 0.39 & 0.05 & 0.18 & 0.36
\end{tabular}

Panel C: Eq. (3)

\begin{tabular}{llllll}
\hline & $\boldsymbol{\beta}_{31}$ & $\boldsymbol{\beta}_{32}$ & $\boldsymbol{\beta}_{33}$ & $\boldsymbol{\beta}_{34}$ & $\sigma$ \\
\hline UK & 0.10 & 0.05 & 0.14 & 0.16 & 0.43 \\
France & 0.03 & 0.24 & 0.29 & 0.15 & $0.60^{*}$ \\
Italy & 0.06 & 0.30 & 0.03 & 0.04
\end{tabular}

Panel D: Eq. (4)

\begin{tabular}{llllll}
\hline & $\boldsymbol{\beta}_{41}$ & $\boldsymbol{\beta}_{42}$ & $\boldsymbol{\beta}_{43}$ & $\boldsymbol{\beta}_{44}$ & 0.02 \\
\hline UK & 0.20 & 0.16 & 0.06 & 0.14 & 0.33 \\
France & 0.07 & 0.10 & 0.08 & 0.13 & 0.05 \\
Italy & 0.08 & 0.06 & 0.05 & 0.19 \\
\hline
\end{tabular}

The $5 \%$ critical value for rejection of the stability hypothesis is 0.47 . The parameters with * are those that reject the hypothesis.

Our data set consists of nominal interest rates on 3 month Eurocurrency deposits on the London market for four countries: Italy, France, UK and Germany. Each country's rate of inflation is based on the consumer price index and the debt represents the outstanding government debt at the end of each period. The exchange rate included in the analysis is the price of $1 \mathrm{DM}$ in the domestic currency. The data sample consists of quarterly data, covering the period from 1978:1 to 1997:1. In the analysis, Germany is considered to be the benchmark country and is exogenous to the system. Taking Germany as exogenous is justified on two grounds; first, it significantly reduces the computational burden associated with the implementation of $\mathrm{M}-\mathrm{ARCH}$ models and preserves the tractability of the model (treating Germany as exogenous reduces the number of parameters for estimation in the second-order moments from 42 to 20); second, it seems reasonable to assume that within Europe, Germany acts as a leader country. ${ }^{7}$

\footnotetext{
${ }^{7}$ Previous empirical studies (Katsimbris \& Miller, 1993) on short-term interest rates within Europe suggest that German leadership is not robust to the inclusion of the United States. The methods used in order to get these results, however, seem rather weak. Indeed, they rely on stationarity tests with low power. The application of more appropriate methodology makes this conclusion controversial and still open to further research. (Bordes, Girardin, \& Marimoutou, 1994).
} 
Table 2

Conditional Mean equations for short-term interest differentials

\begin{tabular}{llrrrr}
\hline & $\boldsymbol{\beta}_{11}$ & \multicolumn{1}{c}{$\boldsymbol{\beta}_{12}$} & \multicolumn{1}{c}{$\boldsymbol{\beta}_{13}$} & \multicolumn{1}{c}{$\boldsymbol{\beta}_{14}$} & $\gamma$ \\
\hline UK & $0.86(56.8)$ & $6.26(1.11)$ & $0.04(2.55)$ & $-0.05(1.10)$ & $0.29(6.50)$ \\
France & $0.58(13.8)$ & $6.46(1.68)$ & $-0.16(3.54)$ & $1.01(1.88)$ & $0.06(17.2)$ \\
Italy & $0.82(21.3)$ & $0.003(0.91)$ & $-0.03(0.54)$ & $0.21(1.85)$ & $0.01(1.68)$ \\
\hline
\end{tabular}

In view of the non-stationarity tests performed, we define the following vector of stationary variables, $x_{t}=\left(i_{t}-i_{t}^{*}, \Delta S_{t+1}, \Delta \pi_{t}, \Delta b_{t}\right)^{\prime}{ }^{8}{ }^{(}\left(i_{t}-i_{t}^{*}\right)$ is defined as the time $t$ differential between the short-term interest rate in country $i$ and Germany. ${ }^{9}$

The conditional mean is influenced by lagged values of the variables. Both the Akaike and Schwarz criteria suggest that one lag in the conditional mean is sufficient. We test each equation of the system for parameter stability following Hansen (1991). Results are presented in Table 1. The vast majority of parameters are stable over the sample, indicating that we can proceed with our model. In fact, most of the evidence of non-stability found is in the variance parameters especially for the interest differential equation (see Panel A). This lends further support to the adoption of the M-ARCH model and hence, the conditional second-order moments follow a M-ARCH (1) structure. As Eq. (7) suggests, the computed conditional variance of the short-term interest rate differential, $h 1$, is allowed to influence the conditional mean equation, making it a M-ARCH (1) in-mean model. In the model, $\alpha$ is a $4 \times 1$ vector of constants, $\beta$ is a $4 \times 4$ matrix of parameter estimates describing the relationship between the level of the differential and the macroeconomic variables, while $\gamma$ is the coefficient on the time-varying risk premium arising from the conditional volatility of the short interest rate differential. In the specification of the secondorder moments, the matrix $\mathbf{V}^{\prime} \mathbf{V}$ captures the long-run covariance structure while the short-run dynamics are captured by the second term on the right hand side of this equation.

\section{Results}

The model outlined in (7) is estimated using the Quasi-maximum likelihood approach of Bollerslev and Wooldridge (1992). We present the main results for each country in Tables 2-4a,b. In each table, the numbers in parentheses are robust $t$-statistics produced by the aforementioned approach.

\subsection{Conditional mean}

As our primary concern is the relationship between the macroeconomic variables and interest differentials, we concentrate on the first row of the matrices in the conditional mean process. The estimated coefficients with robust $t$-statistics are shown in Table 2. The complete estimation of the mean process is available in the Appendix. We find that interest differentials of all three countries

\footnotetext{
${ }^{8}$ We performed a wide range of unit root tests and then proceeded with stationary variables. Unit root test results are available from the authors upon request.

${ }^{9}$ This exercise is conducted as a partial analysis, trying to assess the importance of the identified macroeconomic variables in determining the interest rate differential. A more complete characterisation of the differential could potentially involve many more variables (including cross-county effects) and the associated difficulties in achieving convergence of the log likelihood function.
} 
Table 3

Estimated coefficients of the conditional variance processes

\begin{tabular}{llllllrrr}
\hline & $\mathbf{V}_{11}$ & $\mathbf{V}_{22}$ & $\mathbf{V}_{33}$ & $\mathbf{V}_{44}$ & $a_{11}$ & \multicolumn{1}{c}{$a_{22}$} & $a_{33}$ & $a_{44}$ \\
\hline UK & $1.08(30.2)$ & $0.01(16.4)$ & $3.88(20.2)$ & $1.62(12.1)$ & $0.17(2.16)$ & $-0.05(0.32)$ & $0.09(1.19)$ & $0.40(5.02)$ \\
France & $6.17(51.6)$ & $0.04(20.0)$ & $1.72(18.7)$ & $0.37(14.1)$ & $0.94(360.1)$ & $-0.26(12.9)$ & $-0.05(0.97)$ & $0.33(9.40)$ \\
Italy & $13.1(275.0)$ & $33.86(5.64)$ & $2.82(14.36)$ & $1.19(16.77)$ & $0.79(143.3)$ & $0.32(3.32)$ & $-0.16(2.70)$ & $-0.22(2.95)$ \\
\hline
\end{tabular}

versus Germany is quite persistent. This is shown by the statistical significance of its own first lag. As well as being statistically significant, these coefficients are quite large, indicating a high degree of persistence in the differential. For both the UK and France, the inflation variable is also significantly different from zero, but not for Italy. The positive coefficient for the UK is consistent with the international Fisher hypothesis. However, we find a negative correlation for the French-German differential. This puzzling relationship has already been documented for equity returns and inflation (see Bodie, 1976; Fama \& Schwert, 1977 for the United States and Gultekin, 1983; Solnik, 1983 for a number of other countries) and has generated a large literature trying to offer explanations (see Nelson, 1976; Geske \& Roll, 1983). Finally, the debt variable is both positive and statistically significant for both France and Italy.

Risk, as measured by the conditional volatility of the differential, is found to be a statistically significant determinant of the short-run differential for all countries. The coefficients are small for France and Italy but nevertheless play an important role in explaining the differential. This measure of volatility includes the influences of the variability of the macroeconomic variables considered in the analysis and their covariances with the short interest differential, thereby providing a more suitable measure of the uncertainty inherent in the economic environment.

Therefore we find that the macroeconomic variables identified by Tobin as potentially important determinants of short interest rate differentials exert both a direct and indirect impact on the conditional mean process.

\subsection{Conditional volatility}

Tables 3 and $4 \mathrm{a}, \mathrm{b}$ present the results of our estimation pertaining to the conditional second-order moments. ${ }^{10}$ Table 3 refers to the conditional variances while Tables $4 \mathrm{a}, \mathrm{b}$ contains the covariance estimates. Both tables have robust $t$-statistics in parentheses.

Figs. 1-3 show the conditional standard deviation computed for each of the countries in the analysis. We see that a pattern emerges. For France and Italy, the risk increases in the period before a major realignment, similar to the finding of Gros and Thygesen (1998) when looking at "off-shore" versus "on-shore" interest rates for these countries. The differential was particularly volatile in the early years of the ERM. Whenever, the currency of these countries came under speculative attack, an increase in perceived risk in interest rates is manifest. This can also be seen for the major currency crisis of the 90s (i.e. Sept 92), though the risk is somewhat dwarfed by the extremely volatile period in the early 1980's. For the UK, the story is a little different. While the pattern looks much the

\footnotetext{
${ }^{10}$ We report the elements of $\mathbf{V}$ and $\mathbf{A}$ and their associated statistical significance. To ensure positive definiteness of the covariance matrix, the long run matrix is given by $\mathbf{V}^{\prime \prime} \mathbf{V}$. This is the rationale of the BEKK specification (Engle \& Kroner, 1995). The short-run dynamics are similar.
} 
Table $4 \mathrm{a}$

Coefficients of the long-run conditional covariance processes

\begin{tabular}{lrrrrrr}
\hline & \multicolumn{1}{c}{$\mathbf{V}_{12}$} & $\mathbf{V}_{13}$ & $\mathbf{V}_{23}$ & \multicolumn{1}{c}{$\mathbf{V}_{14}$} & \multicolumn{1}{c}{$\mathbf{V}_{24}$} & \multicolumn{1}{c}{$\mathbf{V}_{34}$} \\
\hline UK & $0.002(2.72)$ & $0.31(1.16)$ & $-1.30(4.36)$ & $-0.79(8.99)$ & $-0.10(0.74)$ & $0.60(4.67)$ \\
France & $-0.04(78.2)$ & $0.86(16.2)$ & $-0.24(1.95)$ & $0.07(9.55)$ & $0.02(0.97)$ & $-0.02(0.66)$ \\
Italy & $1.36(2.39)$ & $-5.24(124.5)$ & $-0.03(0.28)$ & $-1.58(24.7)$ & $0.31(3.56)$ & $0.10(0.97)$ \\
\hline
\end{tabular}

same, the range of movement in the conditional standard deviation demonstrates that the UK/German differential was very much less volatile. Since the UK was not involved in the ERM in the 1980s, it is reasonable to assume that the exchange rate absorbed much of this volatility with interest rates only influenced by contagion effects across neighboring markets. Even in the aftermath of its entry and subsequent exit from the ERM, the volatility of the differential is lower than the others. Perhaps this says something of the markets view of the UK's commitment to defend its exchange rate against the D-mark.

In the long run, the volatility of each of the variables stems both from its own past values (see Table 3 ) and number of statistically significant covariance terms (see Table $4 \mathrm{a}$ ). The diagonal elements of the $\mathbf{V}$ matrices are predominantly statistically significant as are the off-diagonal elements relating the short interest differential to the exchange rate variable $\left(\mathbf{V}_{12}\right)$, the inflation variable $\left(\mathbf{V}_{13}\right)$ and the debt/GDP ratio $\left(\mathbf{V}_{14}\right)$. Likewise our short-run results offer empirical support for the role played by our macroeconomic factors in determining the volatility of the short interest differential. The covariance terms with the interest differential, captured by $a_{12}, a_{13}$ and $a_{14}$ are predominantly statistically significant.

Consequently, we can argue that each of these macroeconomic variables is an important source of volatility in the short-term interest rate differential and hence on the risk premium. This fact may have been ignored in the past as their main role is not in determining the level of the differential but rather in explaining its volatility. Therefore these factors exert an indirect impact on the mean process through the lagged conditional volatility variable. This effect offers empirical support for the existence of a conditional risk premium in interest rate markets, just as Hess and Kamara (2002) and Hodrick (1987) reported for currency and futures markets, respectively.

\section{Concluding remarks}

The aim of this analysis was to understand the channels by which fiscal and monetary policies as well as changes in foreign economies influence interest rate differentials across countries. Using Tobin's portfolio theory we identify potential transmission mechanisms through which these factors may impact the differential. We propose a M-ARCH in-mean model to capture both the effects of macroeconomic

Table $4 \mathrm{~b}$

Coefficients of the short-run conditional covariance processes

\begin{tabular}{lrrrrrr}
\hline & \multicolumn{1}{l}{$a_{12}$} & \multicolumn{1}{c}{$a_{13}$} & \multicolumn{1}{c}{$a_{23}$} & \multicolumn{1}{c}{$a_{14}$} & \multicolumn{1}{c}{$a_{24}$} & \multicolumn{1}{c}{$a_{34}$} \\
\hline UK & $-0.001(0.28)$ & $-0.20(23.3)$ & $-0.003(1.22)$ & $0.22(5.6)$ & $0.005(0.05)$ & $-0.01(0.45)$ \\
France & $-0.01(163.5)$ & $0.18(37.4)$ & $0.004(2.80)$ & $0.01(11.96)$ & $-0.003(0.91)$ & $-0.06(3.29)$ \\
Italy & $-0.009(4.23)$ & $-0.47(27.7)$ & $0.005(1.25)$ & $-0.14(106.5)$ & $0.01(3.43)$ & $0.04(2.03)$ \\
\hline
\end{tabular}




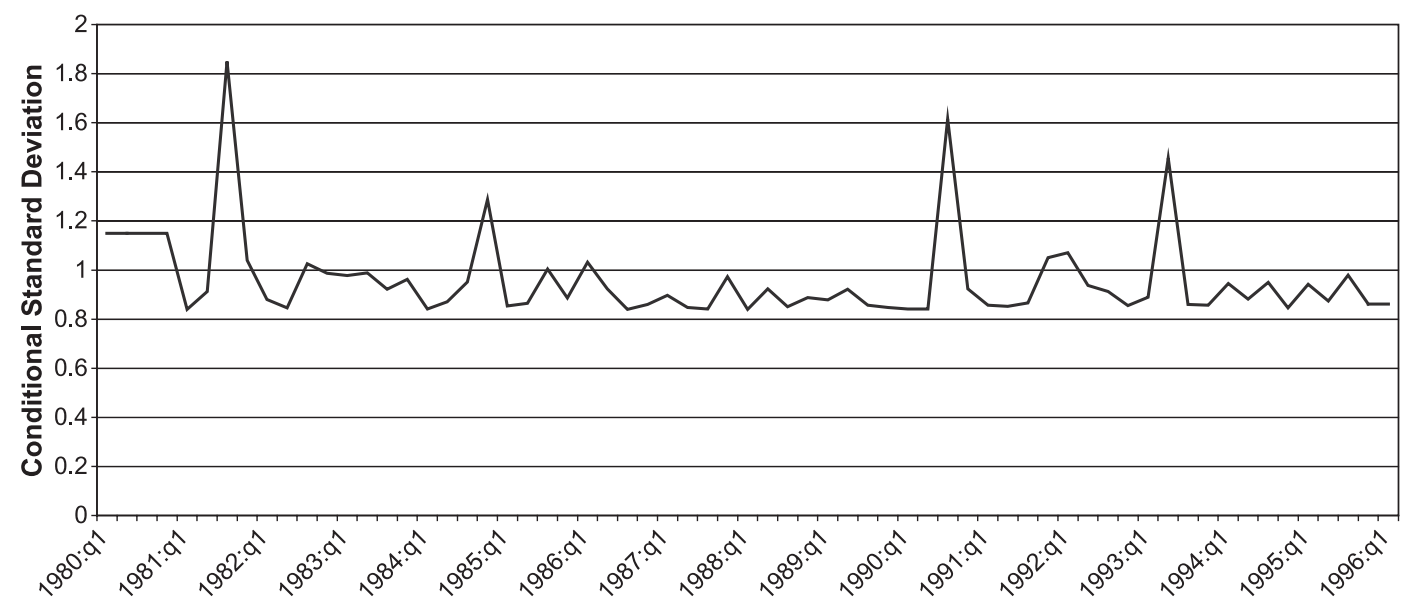

Fig. 1. Conditional standard deviation of UK-German interest rate differential.

variables, intended as proxies for those policies, on the conditional mean and conditional second-order moments of the interest rate differential process. As an illustration we consider a set of European countries prior to the introduction of the common currency and analyze how useful our model is in providing explanations of the short-term interest rate differentials between each country and Germany.

Our empirical results offer evidence that indeed the variables identified play a major role in the determination of the short-term interest rate differential. These variables exert both a direct impact through the conditional mean equation and an indirect impact through the ARCH-in-mean effect. The indirect influence is exerted through the conditional variance, which contains covariance effects with each of the macro variables. The volatility is seen to be at its peak in the approach to the major realignments of the early 1980's for all countries, though the conditional volatility for the UK is significantly lower than the others. This suggests that in the case of the UK, it was its exchange rate with Germany that absorbed economic volatility. This relationship is likely to be overlooked by more

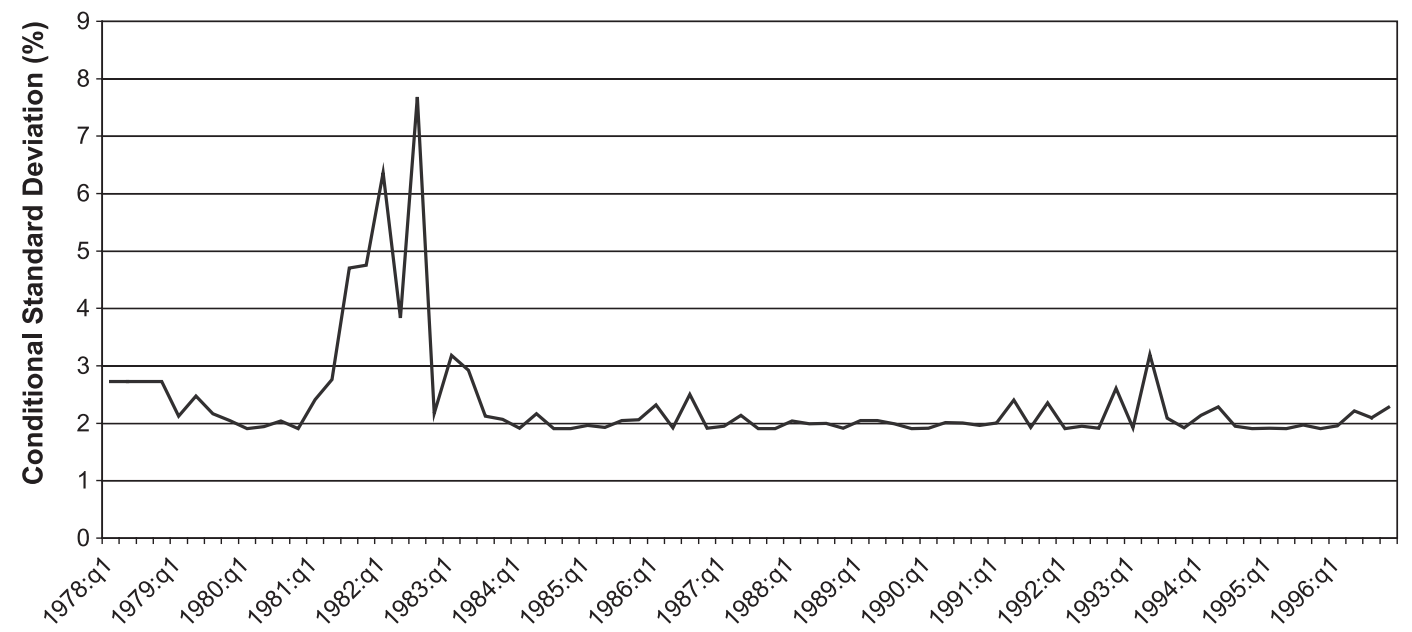

Fig. 2. Conditional standard deviation of French-German interest rate differential. 


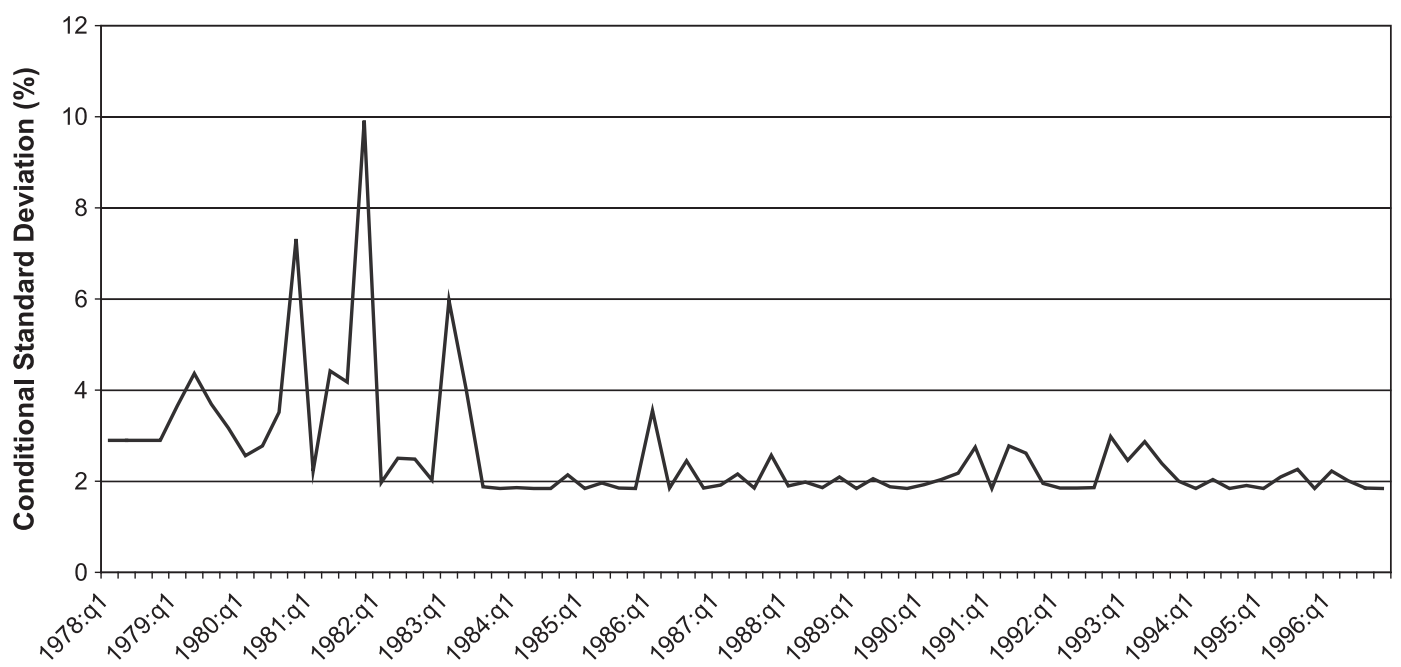

Fig. 3. Conditional standard deviation of Italian-German interest rate differential.

traditional models that focus solely on the first order moments of the process. Kim and Kim (2003) also stress the importance of second-order effects in theoretical modeling of monetary policy adding further significance to our empirical findings.

\section{Appendix A.}

This appendix contains the complete estimation of the conditional mean process. The numbers in parentheses are Bollerslev-Wooldridge robust $t$-statistics.

United Kingdom

$\alpha=\left[\begin{array}{c}0.16(2.21) \\ 0.007(4.39) \\ -1.60(4.64) \\ -1.16(8.05)\end{array}\right], \beta=\left[\begin{array}{cccc}0.86(56.7) & 6.26(1.11) & 0.04(2.54) & -0.05(1.10) \\ -0.006(1.69) & -0.10(0.70) & -0.0002(0.58) & -0.001(0.63) \\ 0.22(2.88) & 34.8(1.27) & -0.59(12.2) & 1.06(8.03) \\ -0.16(5.23) & -1.03(0.11) & 0.05(13.54) & -0.17(2.57)\end{array}\right], \gamma=\left[\begin{array}{c}0.29(6.50) \\ 0 \\ 0 \\ 0\end{array}\right]$

France

$\alpha=\left[\begin{array}{c}0.84(15.5) \\ -0.001(0.40) \\ -0.26(1.76) \\ 1.02(57.3)\end{array}\right], \beta=\left[\begin{array}{cccc}0.57(13.8) & 6.46(1.69) & -0.15(3.54) & 1.01(1.88) \\ 0.003(2.56) & 0.17(2.12) & 0.003(1.32) & -0.005(0.55) \\ 0.07(1.53) & -10.3(3.20) & -0.33(3.17) & 1.07(2.33) \\ 0.02(4.61) & -0.46(0.82) & -0.05(45.0) & 0.14(1.86)\end{array}\right], \gamma=\left[\begin{array}{c}0.06(17.24) \\ 0 \\ 0 \\ 0\end{array}\right]$

Italy

$\alpha=\left[\begin{array}{l}0.50(2.40) \\ 2.46(0.45) \\ 0.82(1.67) \\ 0.25(0.28)\end{array}\right], \beta=\left[\begin{array}{cccc}0.82(21.31) & 0.002(0.91) & -0.03(0.54) & 0.21(1.85) \\ -0.03(0.06) & 0.20(1.32) & 0.82(1.29) & 4.18(1.41) \\ -0.14(2.14) & 0.008(1.25) & -0.25(3.31) & 0.34(1.56) \\ 0.02(0.39) & 0.008(1.42) & 0.005(0.62) & 0.07(1.05)\end{array}\right], \gamma=\left[\begin{array}{c}0.01(1.68) \\ 0 \\ 0 \\ 0\end{array}\right]$ 


\section{References}

Baum, C. F., \& Barkoulas, J. (1996). Time-varying risk premia in the foreign currency futures basis. Journal of Futures Markets, 16, 735-755.

Bodie, Z. (1976). Common stocks as a hedge against inflation. Journal of Finance, 31, 459-470.

Bollerslev, T. (1986). A generalized autoregressive conditional heteroskedasticity. Journal of Econometrics, 31, $307-327$.

Bollerslev, T., Engle, R. F., \& Nelson, D. B. (1994). ARCH models. In R. F. Engle, \& D. L. McFadden (Eds.), Handbook of Econometrics, vol. 4. Elsevier Science B.V.

Bollerslev, T., \& Wooldridge, J. M. (1992). Quasi-maximum likelihood estimation and inference in dynamic models with timevarying covariances. Econometric Reviews, 11, 143-172.

Bordes, C., Girardin, E., \& Marimoutou, V. (1994). Has the EMS become asymmetric? Mimeo, City University Business School.

Clare, A. D., O’Brien, R., Thomas, S. H., \& Wickens, M. R. (1998). Macroeconomic shocks and the domestic CAPM: Evidence from the UK stock market. International Journal of Finance and Economics, 3, 111-126.

Constantinides, G. M., \& Mallaris, A. G. (1995). Portfolio theory. In R. A. Jarrow, V. Maksimovic, \& W. T. Ziemba (Eds.), Handbook of finance. North Holland.

Engle, R. F. (1982). Autoregressive conditional heteroskedasticity with estimates of the variance of UK inflation. Econometrica, 50, 987-1008.

Engle, R. F., \& Kroner, K. F. (1995). Multivariate simultaneous generalized ARCH. Econometric Theory, 11, $122-150$.

Fama, E. F., \& Schwert, G. W. (1977). Asset returns and inflation. Journal of Financial Economics, 5, $115-146$.

Flavin, T. J., \& Limosani, M. G. (2000). Fiscal policy and the term premium in real interest rate differentials. Applied Financial Economics, 10, 413-417.

Flavin, T. J., \& Wickens, M. R. (2003). Macroeconomic influences on optimal asset allocation. Review of Financial Economics, 12, 207-231.

Frankel, J., \& MacArthur, A. (1988). Political versus currency premia in international real interest differentials: A study of forward rates for 24 countries. European Economic Review, 32, 1083-1121.

Frankel, J. A. (1982). In search of the exchange risk premium: A six currency test assuming mean-variance optimisation. Journal of International Money and Finance, 1, 255-274.

Geske, R., \& Roll, R. (1983). The fiscal and monetary linkage between stock returns and inflation. Journal of Finance, 38, $1-33$.

Gros, D., \& Thygesen, N. (1998). European monetary integration. (2nd edition). NY: Addison Wesley Longman.

Gultekin, N. B. (1983). Stock market returns and inflation: Evidence from other countries. Journal of Finance, $38,49-65$.

Hansen, B. (1991). Parameter instability in linear models. Journal of Policy Modeling, 14, 517-533.

Hess, A. C., \& Kamara, A. (2002). Conditional time-varying interest rate risk premia: Evidence from the Treasury bill futures market. Mimeo, University of Washington.

Hodrick, R. J. (1987). The empirical evidence on the efficiency of forward and futures foreign exchange markets. NY: Harwood Academic Publishers.

Katsimbris, G. M., \& Miller, S. M. (1993). Interest rate linkages within the European monetary system: Further analysis. Journal of Money, Credit and Banking, 25, 771-779.

Kim, J., \& Kim, S. (2003). Spurious welfare reversal in international business cycle models. Journal of International Economics, 60, 471-500.

Limosani, M. (2000). What explains real interest rate differentials across European countries? Further empirical analysis. Studi Economici, 55, 99-114.

Markowitz, H. M. (1952). Portfolio selection. Journal of Finance, 46, 469-477.

Nelson, C. R. (1976). Inflation and rates of return on common stock. Journal of Finance, 31, 471-483.

Solnik, B. (1983). The relation between stock prices and inflationary expectations: The international evidence. Journal of Finance, 39, 35-48.

Tobin, J. (1958). Liquidity preference as behaviour towards risk. Review of Economic Studies, 25, 65-86.

Tobin, J. (1982). Money and finance in the macroeconomic process. Journal of Money, Credit and Banking, 4, $171-204$.

Wickens, M. R., \& Smith, P. N. (2002). Macroeconomic sources of FOREX risk, CEPR Discussion Paper 3148. 